\title{
Commentary: See 1—simulate 10,000—do 1; teach 1
}

\author{
David L. Joyce, MD
}

\author{
From the Division of Cardiothoracic Surgery, Medical College of Wisconsin, Hub for Collaborative Medicine, \\ Milwaukee, Wis. \\ Disclosures: Author has nothing to disclose with regard to commercial support. \\ Received for publication Sept 14, 2018; accepted for publication Sept 17, 2018; available ahead of print Nov 7 , \\ 2018. \\ Address for reprints: David L. Joyce, MD, Division of Cardiothoracic Surgery, Medical College of Wisconsin, \\ Hub for Collaborative Medicine, 8701 Watertown Plank Rd, Milwaukee, WI 53226 (E-mail: djoyce@mcw. \\ edu). \\ J Thorac Cardiovasc Surg 2019;157:1575 \\ $0022-5223 / \$ 36.00$ \\ Copyright (c) 2018 by The American Association for Thoracic Surgery \\ https://doi.org/10.1016/j.jtcvs.2018.09.051
}

\section{"Psychologists tell us that in order to learn from experience, two ingredients are necessary: frequent practice and immediate feedback."}

- Richard H. Thaler, 2017

Nobel Laureate in Economics

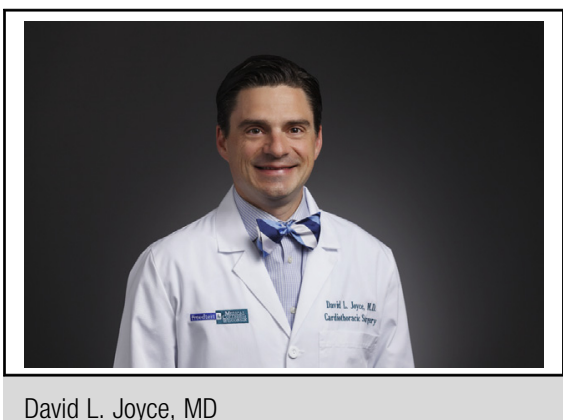

David L. Joyce, MD

\section{Central Message}

Simulation experiences are optimized through realism and feedback.

See Article page 1567.
Like gym memberships, the full benefits of cardiac surgery simulators are often not sought by those who have them. As educators, we regularly preach about the direct relationship between the number of hours in the simulator and the mastery of surgical techniques. Yet, when push comes to shove, few of us deliberately practice what we preach in refining our own skills. In their provocative introduction of the Maastricht mitral simulator, a high-fidelity minimally invasive mitral valve simulator, Nia and colleagues ${ }^{2}$ offer a glimpse of a product that might just nudge us back to the gym where we can take advantage of the benefits of simulation in cardiac surgical education.

From the first-year medical student who leaves behind a nest of knotted suture material attached to every chair in the call room to the professor with a forehead imprint indicating hours spent at the robot-assisted surgery console, surgeons intuitively understand that the value of a simulator depends entirely on the realism of the experience. Sadly, current simulators only crudely approximate most of the technical maneuvers required in cardiac surgery. In many cases, this deficiency in training can be overcome by extensive realworld experience, as it does in cannulation and coronary revascularization procedures. In the case of mitral valve procedures, the clinical experience required to master the nuances and complexities of surgical repair may prove hard to come by. The increasing trend toward lessinvasive and robotic approaches to these repairs ${ }^{3}$ only compounds the imbalance between technical complexity and surgical opportunities needed to master them. By enlisting the expertise of master surgeons in mitral valve repair when crafting a prototype simulator that closely approximates both the geometric arrangement and tissue consistency of these valves, the authors have created a means for trainees to perfect their skills in the gym, so to speak, before applying them in the operating theater.

Although not the first high-fidelity model of mitral surgery, ${ }^{4}$ the new simulator is a major advance over previous iterations by incorporating real-time and objective feedback. Although the technical precision of the software and graphical user interface remain to be validated against clinical practice, the very presence of nonbiased feedback is a major step forward in the design of cardiac surgery simulators.

It is easy to imagine a future in which case preparation involves first performing a virtual procedure based on a three-dimensional rendering of a patient's anatomy, complete with detailed feedback on the precision of needle placement and suture tension. Although by no means perfect, the Maastricht mitral simulator is an important step in the right direction.

The author thanks William Stewart Halsted, MD, father of the modern surgical residency program in the United States, for inspiring the title of this article.

\section{References}

1. Thaler RH. Misbehaving: The Making of Behavioral Economics. New York, NY W.W. Norton \& Company; 2015

2. Nia PS, Daemen JHT, Maessen JG. Development of a high-fidelity minimally invasive mitral valve surgery simulator. J Thorac Cardiovasc Surg. 2019; 157: 1557-74.

3. Schmitto JD, Mokashi SA, Cohn LH. Past, present, and future of minimally invasive mitral valve surgery. J Heart Valve Dis. 2011;20:493-8.

4. Joyce DL, Dhillon TS, Caffarelli AD, Joyce DD, Tsirigotis DN, Burdon TA, et al Simulation and skills training in mitral valve surgery. J Thorac Cardiovasc Surg. 2011;141:107-12. 